\title{
Effect of preoperative long-term opioid therapy on patient outcomes after total knee arthroplasty: an analysis of multicentre population-based administrative data
}

\author{
C. Michael Goplen, MD \\ Sung Hyun Kang, MSc \\ Jason R. Randell, PhD \\ C. Allyson Jones, PT, PhD \\ Donald C. Voaklander, PhD \\ Thomas A. Churchill, PhD \\ Lauren A. Beaupre, PT, PhD
}

Accepted Mar. 17, 2020

\author{
Correspondence to: \\ C. Goplen \\ Division of Orthopaedic Surgery \\ University of Alberta \\ Edmonton AB T6G 2R3 \\ cgoplen@ualberta.ca
}

DOI: $10.1503 /$ cjs.007319
Background: Up to $40 \%$ of patients are receiving opioids at the time of total knee arthroplasty (TKA) in the United States despite evidence suggesting opioids are ineffective for pain associated with arthritis and have substantial risks. Our primary objective was to determine whether preoperative opioid users had worse knee pain and physical function outcomes 12 months after TKA than patients who were opioidnaive preoperatively; our secondary objective was to determine the prevalence of opioid use before and after TKA in Alberta, Canada.

Methods: In this retrospective analysis of population-based data, we identified adult patients who underwent TKA between 2013 and 2015 in Alberta. We used multivariable linear regression to examine the association between preoperative opioid use and Western Ontario and McMaster Universities Osteoarthritis Index (WOMAC) pain and physical function scores 12 months after TKA, adjusting for potentially confounding variables.

Results: Of the 1907 patients, 592 (31.0\%) had at least 1 opioid dispensed before TKA, and $124(6.5 \%)$ were classified as long-term opioid users. Long-term opioid users had worse adjusted WOMAC pain and physical function scores 12 months after TKA than patients who were opioid-naive preoperatively (pain score $\beta=7.7,95 \%$ confidence interval [CI] 4.0 to 11.6; physical function score $\beta=7.8,95 \%$ CI 4.0 to $11.6 ; p<0.001$ for both). The majority $(89$ ([71.8\%]) of patients who were long-term opioid users preoperatively were dispensed opioids 180-360 days after TKA, compared to $158(12.0 \%)$ patients who were opioid-naive preoperatively.

Conclusion: A substantial number of patients were dispensed opioids before and after TKA, and patients who received opioids preoperatively had worse adjusted pain and functional outcome scores 12 months after TKA than patients who were opioidnaive preoperatively. These results suggest that patients prescribed opioids preoperatively should be counselled judiciously regarding expected outcomes after TKA.

Contexte : Jusqu'à $40 \%$ des patients se font prescrire des opioïdes lors d'une chirurgie pour prothèse totale du genou (PTG) aux États-Unis, et ce, malgré des données selon lesquelles les opiö̈des sont inefficaces pour la douleur associée à l'arthrite et comportent des risques substantiels. Notre objectif principal était de déterminer si les patients qui utilisaient déjà des opiö̈des en période préopératoire obtenaient des résultats plus négatifs aux plans de la douleur et du fonctionnement 12 mois après leur PTG, comparativement aux patients qui ne prenaient pas d'opioïdes avant leur intervention; notre objectif secondaire était de mesurer la prévalence du recours aux opioïdes avant et après la PTG en Alberta, au Canada.

Méthodes : Dans cette analyse rétrospective menée sur des données de population, nous avons identifié les patients adultes soumis à une PTG entre 2013 et 2015 en Alberta. Nous avons utilisé un modèle de régression linéaire multivarié pour examiner le lien entre l'utilisation d'opioïdes en période préopératoire et les scores de douleur et de fonctionnement à l'échelle WOMAC (Western Ontario and McMaster Universities Osteoarthritis Index) 12 mois après la PTG, en tenant compte de potentielles variables de confusion.

Résultats : Sur les 1907 patients, 592 (31,0\%) ont reçu au moins 1 opioïde avant leur PTG, et 124 (6,5\%) en étaient considérés des utilisateurs de longue date. Les utilisateurs d'opioïdes de longue date présentaient de moins bons scores WOMAC ajustés pour les domaines de douleur et de fonctionnement 12 mois après la PTG, comparativement aux patients qui n'en prenaient pas avant l'intervention (score de douleur 
$\beta=7,7$, intervalle de confiance [IC] de $95 \% 4,0$ à 11,6 ; score de fonctionnement $\beta=$ $7,8, \mathrm{IC}$ de $95 \% 4,0$ à 11,$6 ; p<0,001$ pour les 2 domaines). La majorité (89 [71,8\%]) des patients utilisateurs d'opioïdes de longue date avant l'intervention se sont fait servir des opioïdes 180-360 jours après la PTG, comparativement à 158 patients $(12,0 \%)$ qui n'en prenaient pas avant l'intervention.

Conclusion : Un nombre substantiel de patients ont reçu des opiö̈des avant et après la PTG, et ceux qui en prenaient avant l'intervention présentaient des scores de douleur et de fonctionnement ajustés plus défavorables 12 mois après la PTG, comparativement aux patients qui n'en prenaient pas avant l'intervention. Selon ces résultats, il faut adresser des conseils judicieux aux patients qui sont déjà sous opioïdes en période préopératoire et les informer des résultats possibles de la PTG.

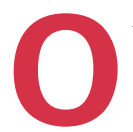

ver the past 20 years, the number of opioids prescribed to manage arthritis has increased dramatically in North America despite emerging evidence suggesting that opioids provide no benefit compared to alternatives such as acetaminophen and ibuprofen. ${ }^{1-4}$ These findings were reflected in the most recent Canadian and US guidelines for opioids for chronic noncancer pain, which recommend a much more limited role for opioids to manage pain associated with arthritis. ${ }^{1,5}$ However, $40 \%$ of patients are still prescribed opioids before total knee arthroplasty (TKA) in the United States. ${ }^{6-8}$ To our knowledge, the prevalence of preoperative opioid prescriptions has not been reported in Canada. It is also unknown whether TKA reduces opioid consumption substantially in these patients, and there is growing concern that TKA may be a risk factor for long-term opioid therapy as a result of excessive postoperative opioid-prescribing practices. ${ }^{9-11}$

As pressure to practise appropriate opioid stewardship grows, prescription of opioids before TKA has prompted substantial research and clinical interest. ${ }^{11-15}$ Patients prescribed opioids before TKA are reported to have higher 90-day complication rates and rates of revision surgery within 1 year of TKA than patients who were opioid-naive preoperatively. ${ }^{6}, 16$ Patients prescribed opioids preoperatively also had worse pain and lower functional improvement after TKA than those who were not prescribed preoperative opioids. ${ }^{13,15,17}$ However, these studies failed to account for important differences, such as rates of depression and preoperative pain, and functional scores between the 2 groups. ${ }^{15}$ Given that these additional patient factors are also associated with both long-term opioid use and worse clinical outcomes after TKA, the extent to which opioid use independently affects clinical outcomes remains uncertain. ${ }^{18-20}$

The primary objective of this study was to determine whether patients with long-term opioid use before TKA had worse self-reported knee pain and lower functional outcome scores 12 months after TKA than those who did not use opioids preoperatively, controlling for potential confounding factors. Our secondary objective was to determine the prevalence of opioid use before and after TKA in Alberta, Canada.

\section{Methods}

\section{Study design}

In this retrospective review of individual-level data, we identified patients who underwent primary elective unilateral TKA between Jan. 1, 2013, and Dec. 31, 2015, in 1 of 13 hospitals in Alberta. Patients who underwent contralateral TKA were included only once, for the first procedure. Patients were excluded if they underwent contralateral TKA or revision TKA within 12 months of the index procedure. Patients with missing data (comorbidity, or preoperative or 12-month postoperative Western Ontario and McMaster Universities Osteoarthritis Index [WOMAC] score $^{21}$ ) were also excluded. We followed the Strengthening the Reporting of Observational Studies in Epidemiology (STROBE) guidelines. ${ }^{22}$ The study protocol was approved by the Research Ethics Board at the University of Alberta (Pro00076296).

\section{Data sources}

We obtained surgical data from the Alberta Bone and Joint Health Institute (ABJHI), a nonprofit third-party organization that collects provincial data for all TKA procedures performed in Alberta. All adult (age $\geq 18 \mathrm{yr}$ ) patients who underwent elective TKA in the data set were flagged with the use of TKA-specific codes of the enhanced Canadian version of the International Statistical Classification of Diseases and Related Health Problems, 10th Revision (Appendix 1, Supplemental Table S1, available at canjsurg.ca/007319-a1). The ABJHI captured prespecified preoperative comorbidities from the Canadian Institute for Health Information electronic abstract for each patient (Appendix 1, Supplemental Table S1). The institute also collected preoperative and 12-month postoperative WOMAC scores from the 6 centralized multidisciplinary hip and knee intake clinics in the province.

We obtained opioid data from the Pharmaceutical Information Network, a provincial repository that maintains individual-level pharmacotherapy records and includes dispensing information from all community pharmacies in 
Alberta, regardless of insurance coverage. A record is created in the network each time a medication is dispensed from a pharmacy in the province and contains the Drug Identification Number, Anatomical Therapeutic Chemical code, date dispensed, dosage and duration (days supplied). Each Pharmaceutical Information Network entry is linked to the patient's Unique Lifetime Identifier, a unique number assigned to all people who receive health care services in the province. Each patient's Pharmaceutical Information Network profile was queried by means of opioid-specific Anatomical Therapeutic Chemical codes for the 365 days before and after the index surgery to determine his or her opioid-dispensing history (Appendix 1, Supplemental Table S2). The end date for each dispensation was then calculated by adding the duration to the dispensing date for each Pharmaceutical Information Network entry.

We converted individual opioid prescriptions to a daily morphine equivalent dose (MED) by multiplying the daily dosage for each opioid by the corresponding MED to allow for standardized comparison across different opioid compounds. ${ }^{1}$ Morphine conversion factors were based on published conversion factors ${ }^{23}$ that align with Canadian opioid-prescribing guidelines. ${ }^{1}$ We classified opioid compounds as weak (tramadol and codeine) or strong (all remaining opioids). ${ }^{24}$

We linked all data sets deterministically using patients' Unique Lifetime Identifiers, which had been scrambled by means of an algorithm that deidentified them but still preserved the ability to link across data sets.

\section{Primary outcomes}

The primary outcomes of interest were WOMAC pain and physical function scores 12 months after TKA. The WOMAC is a validated disease-specific patient-reported outcome instrument used to measure joint pain, stiffness and physical function. ${ }^{21}$ Scores ranging from 0 to 100 are generated for each domain with the use of a Likert scale, with higher scores indicative of better outcome.

\section{Classification of opioid use}

Patients with long-term opioid use before TKA were defined as those who had 90 days or more of continuous opioid dispensing within 180 days before the procedure. These parameters were consistent with the definition of long-term opioid therapy. ${ }^{25}$ Patients with intermittent opioid use preoperatively had recorded opioid dispensing within 180 days before TKA but did not meet the threshold parameters for long-term opioid use. Patients who were opioid-naive preoperatively did not have recorded opioid dispensing within 180 days before TKA. The 180day opioid-free period has been previously used in studies investigating long-term opioid therapy and is the established threshold for opioid discontinuation. ${ }^{26,27}$
We defined those with long-term, intermittent or no opioid use postoperatively using the same parameters as we used to define preoperative opioid use, but the medication use period was increased from 180 days to 360 days after the index TKA procedure. The maximum allowable refill gap between prescriptions in an opioid use episode was 14 days or 0.5 times the preceding prescription length, whichever was greater. ${ }^{28,29}$

\section{Covariates}

Clinically meaningful demographic and medical variables were age, sex, preoperative WOMAC pain score, WOMAC physical function score, history of stroke, pulmonary disease, cardiac disease, liver disease, renal dysfunction, diabetes, obesity and depression. We chose these covariates to include factors thought to influence postoperative clinical outcome scores after TKA and account for potential confounders. ${ }^{30-36}$

\section{Statistical analysis}

We used descriptive statistics to characterize preoperative opioid-dispensing patterns including dosage (MED) and duration. We reported medians and interquartile ranges (IQRs) for nonparametric variables, and means with 95\% confidence interval (CI) or standard deviation (SD) if variables were normally distributed. We compared continuous outcomes using the Student $t$ test or 1-way analysis of variance for normally distributed variables. We used a post hoc Bonferroni correction to determine pairwise differences between groups. We presented differences between preand postoperative opioid use as percent difference. ${ }^{37}$

To examine the effects of preoperative opioid use, 12-month WOMAC pain score and 12-month WOMAC physical function score, we developed separate multivariable regression models for each outcome. We determined final parsimonious models for 12-month WOMAC pain score and physical function score using a purposeful selection procedure with predictors deemed significant $(p<0.2)$ after univariate analysis carried forward to the multivariable model. Age and sex, deemed clinically meaningful, were force entered in the model regardless of their statistical significance. Forward, backward and stepwise selection with adjusted $R^{2}$, the Akaike information criterion, the Bayesian information criterion, the Schwarz Bayesian criterion and Mallows Cp cross-validation as criteria showed the final models to be robust to the selection procedure used. We produced model diagnostics and influential plot based on the Cook distance to check model assumptions and fit. No collinearity among continuous predictors was noted with the Pearson correlation coefficient. Significance was set at $p<0.05$. We used SAS version 9.4 (SAS Institute) for data linkage and preparation, and Stata version 13 (StataCorp) for final regression models. 


\section{Results}

Of the 16049 patients who underwent primary elective TKA between 2013 and 2015 in Alberta, 14142 were excluded: 3813 underwent contralateral TKA within 1 year, 94 underwent revision TKA within 1 year, 250 had missing comorbidity data, and 9985 had a missing preoperative or 12-momth WOMAC score. The remaining 1907 patients constituted our study cohort. The characteristics of excluded patients were comparable to those of the study population (Appendix 1, Supplemental Tables S3 and S4).

The mean age of the study population was 66.6 (SD 8.7 ) years, and 1234 patients (64.7\%) were female. A total of 540 patients (28.8\%) were obese, $388(20.3 \%)$ had a history of diabetes, and 301 (15.8\%) had a history of depression (Table 1). Almost one-third of patients (592 [31.0\%]) had at least 1 opioid prescription dispensed within 180 days before surgery, and $124(6.5 \%)$ were classified as long-term opioid users preoperatively.

A total of 1970 individual opioid prescriptions dispensed within 180 days before TKA were identified, 918 in the long-term use group and 1052 in the intermittent use group. Long-term users had a higher number of strong opioids dispensed than intermittent users (420 v. 144), and intermittent users had a higher number of weak opioids dispensed than long-term users (908 v. 498). Patients with long-term opioid use preoperatively were younger than those who were opioid-naive preoperatively (mean age 64.0 [SD 8.5] yr v. 66.9 [SD 8.5] yr, $p<0.001$ ), and betweengroup differences were observed in rates of obesity, depression, history of stroke, liver disease, cardiac disease and pulmonary disease, but not diabetes or renal disease (Table 1).

There were significant differences in the preoperative WOMAC pain and physical function scores among the 3 groups (Table 1). Patients who were opioid-naive preoperatively had higher preoperative pain and physical function scores than those with long-term or intermittent opioid use preoperatively ( $p<0.001$ for both).

\section{Pain and physical function at 12 months}

Patients with long-term opioid use preoperatively had a mean 12-month WOMAC pain score of 69.0 (95\% CI 64.5 to 73.5$)$ and a mean physical function score of 67.9 (95\% CI 63.5 to 72.4) (Figure 1). The corresponding values for those with intermittent opioid use preoperatively were 73.0 (95\% CI 71.7 to 76.1 ) and 71.3 (95\% CI 69.3 to 73.3 ). Patients who were opioid-naive preoperatively had a significantly higher mean pain score $(80.3,95 \%$ CI 79.2 to

\begin{tabular}{|c|c|c|c|c|c|}
\hline \multirow[b]{2}{*}{ Characteristic } & \multicolumn{4}{|c|}{ Preoperative classification; no. (\%) of patientst } & \multirow[b]{2}{*}{$p$ value } \\
\hline & $\begin{array}{c}\text { Total cohort } \\
n=1907\end{array}$ & $\begin{array}{l}\text { Opioid-naive } \\
n=1315\end{array}$ & $\begin{array}{l}\text { Intermittent opioid use } \\
\qquad n=468\end{array}$ & $\begin{array}{l}\text { Long-term opioid use } \\
\qquad n=124\end{array}$ & \\
\hline Age, mean $\pm S D$, yr & $66.6 \pm 8.7$ & $66.9 \pm 8.5$ & $66.1 \pm 9.2$ & $64.0 \pm 8.5 \neq \S$ & 0.002 \\
\hline \multicolumn{6}{|l|}{ Sex } \\
\hline Female & $1234(64.7)$ & $845(64.3)$ & $309(66.0)$ & $80(64.5)$ & \\
\hline Male & $673(35.3)$ & $470(35.7)$ & $159(34.0)$ & $44(35.5)$ & 0.8 \\
\hline \multicolumn{6}{|l|}{ Comorbidities } \\
\hline Depression & $301(15.8)$ & $176(13.4)$ & 87 (18.6) & $38(30.6)$ & $<0.001$ \\
\hline Stroke & $28(1.5)$ & $18(1.4)$ & $7(1.5)$ & $3(2.4)$ & $<0.001$ \\
\hline Pulmonary disease & $168(8.8)$ & $105(8.0)$ & $41(8.8)$ & $22(17.7)$ & 0.001 \\
\hline Cardiac disease & $456(23.9)$ & $295(22.4)$ & $122(26.1)$ & $39(31.4)$ & 0.04 \\
\hline Diabetes & $388(20.3)$ & $253(19.2)$ & $102(21.8)$ & $33(26.6)$ & 0.1 \\
\hline Renal disease & $48(2.5)$ & $29(2.2)$ & $15(3.2)$ & $4(3.2)$ & 0.4 \\
\hline Obesity & $549(28.8)$ & $356(27.1)$ & $149(31.8)$ & $44(35.5)$ & 0.04 \\
\hline Liver disease & $22(1.2)$ & $13(1.0)$ & $8(1.7)$ & $1(0.8)$ & 0.03 \\
\hline \multicolumn{6}{|c|}{ Mean preoperative WOMAC score $(95 \% \mathrm{CI})$} \\
\hline Pain & 45.9 (45.0 to 46.7$)$ & 47.6 (46.6 to 48.5$)$ & 42.4 (40.8 to 44.0$)$ & 40.6 (37.4 to 43.9$) \neq$ & $<0.001$ \\
\hline Physical function & 45.5 (44.8 to 46.3$)$ & $47.0(46.0$ to 47.0$)$ & 42.9 (41.3 to 44.4$)$ & 40.5 (37.5 to 43.6$) \neq$ & $<0.001$ \\
\hline \multicolumn{6}{|l|}{ Preoperative opioid use } \\
\hline Median MED (IQR) & $3.3(15.3)$ & - & $4.6(9.4)$ & $58.2(79.3)$ & $<0.001$ \\
\hline $\begin{array}{l}\text { No. of days in previous } 180 \mathrm{~d} \text { on } \\
\text { which opioid used, mean }(95 \% \mathrm{Cl})\end{array}$ & 45.4 (41.7 to 49.1$)$ & - & 34.4 (31.5 to 37.3 ) & $152.6(148.0$ to 157.2$)$ & $<0.001$ \\
\hline \multicolumn{6}{|c|}{$\begin{array}{l}\mathrm{Cl}=\text { confidence interval; IQR }=\text { interquartile range; } \mathrm{MED}=\text { morphine equivalent dose; } \mathrm{SD}=\text { standard deviation; WOMAC = Western Ontario and McMaster Universities Osteoarthritis Index } \\
{ }^{*} \text { Analysis of variance for cohort and Bonferroni corrections were used for multiple pairwise comparisons for normally distributed continuous variables. } \\
\dagger \text { Except where noted otherwise. } \\
\neq p<0.05 \text { for difference between opioid-naive patients and long-term opioid users. } \\
\S p<0.05 \text { for difference between intermittent and long-term opioid users. }\end{array}$} \\
\hline
\end{tabular}




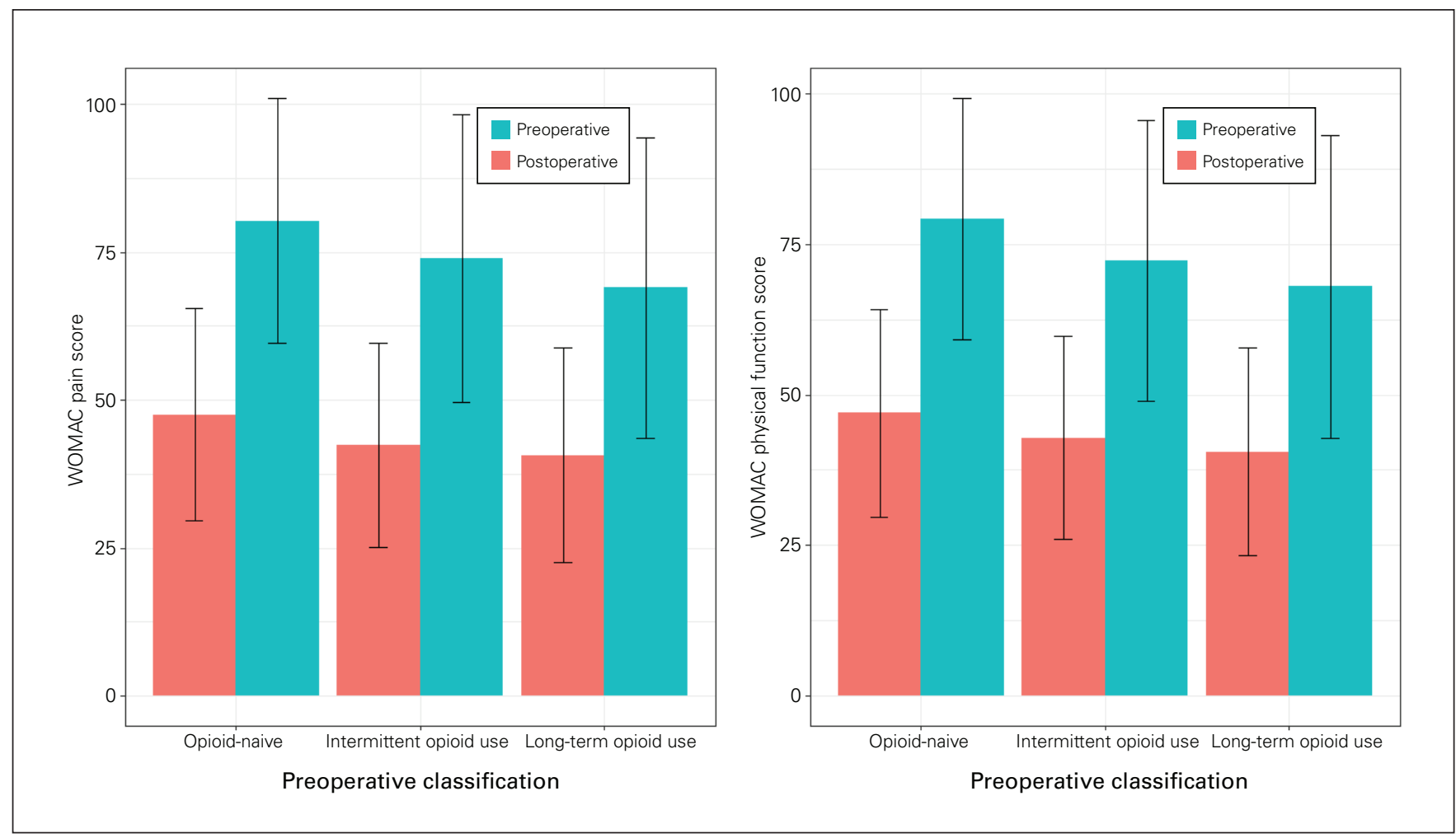

Fig. 1. Unadjusted pre- and postoperative Western Ontario and McMaster Universities Osteoarthritis Index (WOMAC) pain and physical function scores, stratified by preoperative opioid use. Scores were standardized to 100 , with 100 representing the best possible score. Error bars represent standard deviation.

$81.5)$ and physical function score $(72.2,95 \%$ CI 70.1 to 74.2) than long-term opioid users and intermittent opioid users ( $p<0.001$ for all) (Figure 1).

Preoperative opioid use was associated with worse 12-month pain and physical function outcomes than no opioid use preoperatively (Table 2). Age, lower preoperative WOMAC scores, cardiac disease, liver disease, pulmonary disease, diabetes and depression were also associated with worse 12-month pain scores on univariable analysis. Lower preoperative physical function scores, obesity, cardiac disease, pulmonary disease and depression were all associated with lower 12-month physical function scores.

After adjustment for preoperative pain and physical function scores, age, sex, depression, pulmonary disease, cardiac disease and liver disease, both intermittent and long-term opioid use preoperatively were still associated with worse 12 -month pain scores compared to no opioid use preoperatively (Table 2). Similarly, after we controlled for age, sex, depression, diabetes, pulmonary disease and cardiac disease, 12-month physical function scores were on average 5.2 (95\% CI 3.1 to 7.4 ) units worse for intermittent opioid users and 7.8 (95\% CI 4.0 to 11.6) units worse for long-term opioid users than for opioid-naive patients (Table 2).

Significant interactions were found between opioid use and depression in both pain and physical function models (Appendix 1, Supplemental Tables S5 and S6). Long-term opioid users with a history of depression had 12-month pain scores that were on average 13.3 (95\% CI 5.9 to 20.7) units lower and physical function scores that were on average 14.9 (95\% CI 7.8 to 22.0 ) units lower than those for opioid-naive patients without a history of depression.

\section{Postoperative opioid use}

A total of 1606 individual opioid prescriptions dispensed 180-360 days postoperatively were identified, 871 among those with long-term opioid use preoperatively and 735 among those with intermittent opioid use preoperatively. Of the 1907 patients, 448 (23.5\%) were dispensed opioids during this period: $158(12.0 \%)$ of those who were opioidnaive preoperatively, 201 (42.9\%) of those with intermittent opioid use preoperatively and $89(71.8 \%)$ of those with long-term opioid use preoperatively (Figure 2). Codeine, tramadol and oxycodone were the most commonly dispensed opioids both pre- and postoperatively (Table 3). There was no difference in mean treatment duration between preoperative and postoperative prescriptions ( $23.4 \mathrm{~d}$ v. $25.8 \mathrm{~d}, p=0.6)$.

\section{Discussion}

Using established parameters to define long-term opioid therapy and adjusting for significant differences in patient characteristics, including a history of depression and preoperative WOMAC pain and functional scores, we found 
Table 2. Unadjusted and adjusted parameter estimates for Western Ontario and McMaster Universities Osteoarthritis Index pain and physical function scores 12 months postoperatively

\begin{tabular}{|c|c|c|c|c|c|c|c|c|}
\hline \multirow[b]{2}{*}{ Variable } & \multicolumn{4}{|c|}{ Pain } & \multicolumn{4}{|c|}{ Physical function } \\
\hline & $\begin{array}{l}\text { Crude } \beta \\
(95 \% \mathrm{Cl})\end{array}$ & $p$ value & $\begin{array}{l}\text { Adjusted } \beta \\
(95 \% \mathrm{Cl})\end{array}$ & $p$ value & $\begin{array}{l}\text { Crude } \beta \\
(95 \% \mathrm{Cl})\end{array}$ & $p$ value & $\begin{array}{l}\text { Adjusted } \beta \\
(95 \% \mathrm{Cl})\end{array}$ & $p$ value \\
\hline Sex & & 0.3 & & 0.99 & & 0.1 & & 0.6 \\
\hline Female & 1 (reference) & & 1 (reference) & & 1 (reference) & & 1 (reference) & \\
\hline Male & $1.2(-0.9$ to 3.3$)$ & & $-0.1(-2.0$ to 2.0$)$ & & $1.6(-0.4$ to 3.6$)$ & & 0.6 (-1.4 to 2.5$)$ & \\
\hline Age & 0.2 (0.1 to 0.3 ) & 0.003 & $0.1(-0.1$ to 0.2$)$ & 0.08 & $0.1(-0.1$ to 0.1$)$ & 0.8 & $0.1(-0.1$ to 0.1$)$ & 0.8 \\
\hline $\begin{array}{l}\text { Preoperative } \\
\text { WOMAC score }\end{array}$ & $0.4(0.3$ to 0.4$)$ & $<0.001$ & $0.3(0.3$ to 0.4$)$ & $<0.001$ & $0.4(0.4$ to 0.5$)$ & $<0.001$ & $0.4(0.3$ to 0.4$)$ & $<0.001$ \\
\hline \multicolumn{9}{|c|}{ Preoperative opioid use } \\
\hline Opioid-naive & 1 (reference) & & 1 (reference) & & 1 (reference) & & 1 (reference) & \\
\hline Intermittent & $-6.4(-8.7$ to -4.1$)$ & $<0.001$ & $-4.3(-6.6$ to -2.1$)$ & $<0.001$ & $-7.0(-9.3$ to -4.8$)$ & $<0.001$ & $-5.2(-7.4$ to -3.1$)$ & $<0.001$ \\
\hline Long-term & $-11.4(-15.4$ to -7.3$)$ & $<0.001$ & $-7.7(-11.6$ to -3.7$)$ & $<0.001$ & $-11.3(-15.2$ to -7.4$)$ & $<0.001$ & $-7.8(-11.6$ to -4.0$)$ & $<0.001$ \\
\hline \multicolumn{9}{|l|}{ Comorbidities } \\
\hline Depression & $-5.2(-7.9$ to -2.4$)$ & $<0.001$ & $-2.6(-5.3$ to 0.1$)$ & 0.06 & $-5.5(-8.0$ to -2.7$)$ & $<0.001$ & $-2.8(-5.3$ to -0.3$)$ & 0.03 \\
\hline Diabetes & $-5.4(-7.8$ to -2.9$)$ & $<0.001$ & $-3.7(-6.0$ to -1.3$)$ & 0.002 & $-4.5(-6.8$ to -2.0$)$ & $<0.001$ & $-2.5(-4.8$ to -0.2$)$ & 0.03 \\
\hline Cardiac disease & $-3.2(-5.5$ to -0.8$)$ & 0.008 & $-2.3(-4.7$ to -0.1$)$ & 0.048 & $-3.9(-6.2$ to -1.6$)$ & 0.001 & $-2.2(-4.4$ to 0.1$)$ & 0.06 \\
\hline Liver disease & $-9.2(-18.6$ to 0.1$)$ & 0.05 & $-8.0(-16.9$ to 0.9$)$ & 0.08 & $-6.5(-15.5$ to 2.6$)$ & 0.2 & - & - \\
\hline $\begin{array}{l}\text { Pulmonary } \\
\text { disease }\end{array}$ & $-4.6(-8.1$ to -1.1$)$ & 0.01 & $-3.3(-6.7$ to 0.1$)$ & 0.05 & $-5.3(-8.7$ to -1.9$)$ & 0.002 & $-2.9(-6.2$ to 0.3$)$ & 0.08 \\
\hline Obesity & $-2.1(-4.3$ to 0.2$)$ & 0.07 & - & - & $-2.2(-4.4$ to -0.1$)$ & 0.04 & - & - \\
\hline Stroke & $-2.9(-11.2$ to 5.5$)$ & 0.5 & - & - & $-3.6(-11.6$ to 4.5$)$ & 0.4 & - & - \\
\hline Renal disease & $-3.9(-10.3$ to 2.5$)$ & 0.2 & - & - & $-4.7(-10.8$ to 1.5$)$ & 0.1 & - & - \\
\hline
\end{tabular}

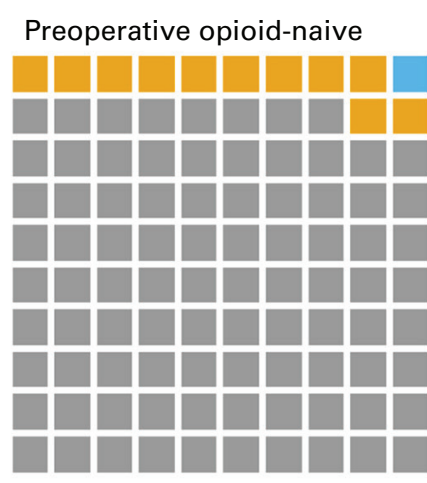

Preoperative long-term opioid use

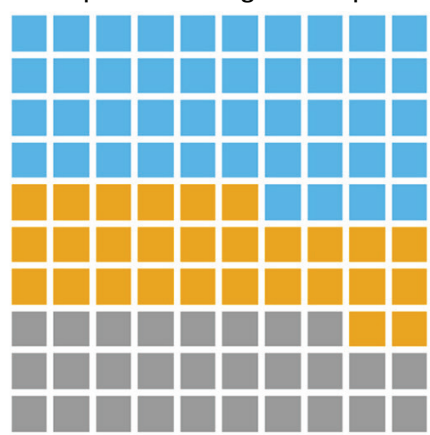

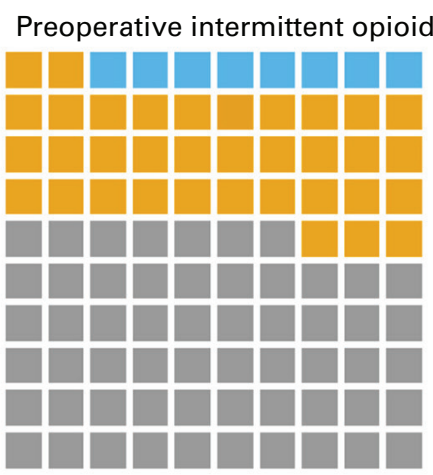

Postoperative no opioid use

Postoperative no opioid use

Postoperative intermittent opioid use

Postoperative long-term opioid use

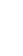




\begin{tabular}{|c|c|c|c|c|c|c|c|c|c|}
\hline \multirow[b]{2}{*}{ Opioid } & \multicolumn{3}{|c|}{ Total cohort, \% } & \multicolumn{3}{|c|}{ Intermittent opioid use, \% } & \multicolumn{3}{|c|}{ Long-term opioid use, \% } \\
\hline & Preoperative & Postoperative & $\begin{array}{c}\text { Percent } \\
\text { difference* }\end{array}$ & Preoperative & Postoperative & $\begin{array}{c}\text { Percent } \\
\text { difference* }\end{array}$ & Preoperative & Postoperative & $\begin{array}{c}\text { Percent } \\
\text { difference* }\end{array}$ \\
\hline Codeine & 40.25 & 37.04 & -3.21 & 50.76 & 53.06 & 2.30 & 28.21 & 23.62 & -4.59 \\
\hline Tramadol & 31.12 & 27.97 & -3.15 & 35.55 & 32.93 & -2.62 & 26.03 & 23.74 & -2.29 \\
\hline Oxycodone & 11.22 & 18.58 & 7.36 & 5.32 & 8.98 & 3.66 & 17.97 & 26.61 & 8.64 \\
\hline Morphine & 6.45 & 2.86 & -3.59 & 1.81 & 1.36 & -0.45 & 11.76 & 4.13 & -7.63 \\
\hline Hydromorphone & 5.53 & 7.40 & 1.87 & 3.23 & 2.86 & -0.37 & 8.17 & 11.24 & 3.07 \\
\hline Fentanyl & 0.76 & 4.60 & 3.84 & 0.76 & 0.00 & -0.76 & 0.76 & 8.49 & 7.73 \\
\hline Othert & 4.67 & 1.55 & -3.12 & 2.58 & 0.81 & -1.77 & 7.08 & 2.17 & -4.91 \\
\hline
\end{tabular}

that patients with long-term opioid use preoperatively had worse pain and physical function outcomes 12 months after TKA than patients who had not used opioids preoperatively. The difference between the 2 groups approached the threshold considered clinically important for WOMAC pain and physical function scores after TKA. ${ }^{38}$ These results substantiate previous findings that patients prescribed opioids preoperatively had worse clinical outcomes after TKA than those who were not, even after risk adjustment. ${ }^{13,15,17,39,40}$ However, previous investigators used crude parameters to classify preoperative opioid use and did not adjust for important group differences, such as worse preoperative pain and physical function scores and higher rates of depression among those prescribed opioids preoperatively..$^{13,17,39}$

Opioid-induced hyperalgesia has been hypothesized to explain why patients with opioid use preoperatively have worse pain and functional outcomes after TKA. ${ }^{15}$ Opioid-induced hyperalgesia is a process whereby patients receiving long-term opioid treatment have a paradoxically increased response to painful stimuli. ${ }^{20,41,42}$ Chu and colleagues ${ }^{42}$ prospectively evaluated opioidinduced hyperalgesia in patients with chronic pain; 1 month after starting oral morphine therapy, patients reported hyperalgesia, whereas controls did not. Cohen and colleagues ${ }^{43}$ reported that patients receiving longterm opioid therapy had higher pain intensity scores and worse patient-reported unpleasantness scores than patients who were not exposed to opioids. It is thought that long-term opioid therapy can disrupt the endogenous opioid system in regions of the brain such as the limbic system and alter how a person interprets pain and perceives disability. ${ }^{20,30}$

Similar to US reports, ${ }^{7,11,44}$ a substantial proportion $(31.0 \%)$ of patients in the current study were dispensed opioids within 180 days before TKA, and $6.5 \%$ were longterm opioid users. In contrast, in an Australian study, 5\% of patients awaiting TKA were considered opioid users. ${ }^{45}$ Although it may appear that there were lower rates of preoperative opioid use in the Australian study than in the US studies, definitional parameters (e.g., crude refill-based definitions used in the US studies) may have affected the reported rates, in addition to possible physician- and geography-specific prescribing practices. ${ }^{7,11,40,45}$ Hansen and colleagues ${ }^{45}$ used parameters that aligned more closely with our definition of long-term opioid use and reported an overall opioid dispensing rate before TKA of $38.6 \%$, comparable to our observed rate of $31 \%$.

The absolute number of opioids dispensed in our cohort was reduced after TKA, but the proportion of strong opioid prescriptions dispensed increased postoperatively. This is concerning, as strong opioids such as oxycodone and hydromorphone have higher rates of misuse and abuse. ${ }^{1}$ In addition, few patients who were opioidnaive preoperatively transitioned from short-term to longterm use after TKA, but $44 \%$ of those with long-term opioid use preoperatively remained long-term users after TKA. These results are consistent with those of Hadlandsmyth and colleagues, ${ }^{28}$ who reported that $2 \%$ of US veterans who were opioid-naive before TKA were long-term opioid users 1 year after TKA, and $57 \%$ of those who were long-term opioid users preoperatively remained long-term users at 1 year; in addition, a substantial number of patients had intermittent opioid dispensing postoperatively. This raises concerns, as with every extra day that a patient is prescribed opioids, the likelihood of transitioning to long-term opioid therapy increases. ${ }^{46}$

\section{Limitations}

A strength of our study was our ability to detect opioid use within a province-wide database that represents a general population, as Canada provides universal coverage of physician and hospital services to all residents and our findings were not restricted to a single centre or surgeon. In addition, our comprehensive database and methodology not only enabled detailed analysis of each prescription's formation, dosage and duration both preoperatively and postoperatively, but also allowed us to relate preoperative opioid use to adjusted postoperative WOMAC scores. 
Limitations include the assumption that opioid dispensing is a surrogate for patient consumption. However, it has been reported that administrative data are more accurate than patient-reported use; patients underreported opioid use by as much as $46 \%$ before TKA owing to the perceived stigma of disclosing opioid use to physicians. ${ }^{47,48}$ A substantial number of patients who had incomplete WOMAC scores were excluded from our cohort. This is not unexpected: Alberta is the fourthlargest Canadian province in both size and population, with about 4 million residents distributed across more than $600000 \mathrm{~km}^{2}$, which causes follow-up challenges for Alberta's centralized hip and knee clinics, as patients are often asked to travel long distances to attend appointments. However, the clinical characteristics of patients with incomplete WOMAC data were comparable to those of patients who were included in the study. These findings are consistent with those of Choi and colleagues, ${ }^{49}$ who reported that the characteristics and postoperative WOMAC scores of patients who attended follow-up after TKA were similar to those of patients who did not. Owing to the limitations of our data set, we were not able to determine whether wait time to surgery influenced opioid use or outcomes after TKA. Finally, our surgical data were complete up to Dec. 31, 2015, and opioid data to Dec. 31, 2016. Future work detailing how opioid prescribing changed in response to Canada's opioid prescribing guidelines, published in $2017,{ }^{1}$ will provide important information to health care providers and policy-makers.

\section{Conclusion}

A substantial number of patients were dispensed opioids before and after TKA. Patients who received opioids preoperatively had worse adjusted WOMAC pain and functional outcome scores 12 months after TKA than patients who were opioid-naive preoperatively. Our results support North America's movement to transition away from opioids to manage chronic pain associated with arthritis, as these patients have been shown to have worse patient-reported outcomes after TKA and are more likely to remain long-term opioid users postoperatively. ${ }^{1,5}$ With the introduction of opioid stewardship, postoperative opioid-prescribing practices are increasingly being scrutinized in recognition that a subset of patients are at risk for persistent opioid use after TKA. More research is needed to further understand risk factors associated with persistent postoperative opioid use and whether standardized, evidence-based opioidprescribing programs can reduce the duration and dosage postoperatively.

Acknowledgement: The authors thank the Alberta Bone and Joint Institute for providing research support and data analysis.
Affiliations: From the Department of Surgery, University of Alberta, Edmonton, Alta. (Goplen, Beaupre, Churchill); the School of Public Health, University of Alberta, Edmonton, Alta. (Randell, Jones, Voaklander); the Department of Physical Therapy, University of Alberta, Edmonton, Alta. (Randell, Jones, Beaupre); and the Alberta Bone and Joint Institute, Calgary, Alta. (Kang).

Competing interests: None declared.

Contributors: C.M. Goplen, J.R. Randell, C.A. Jones, D.C. Voaklander and L.A. Beaupre designed the study. C.M. Goplen and L.A. Beaupre acquired the data, which all authors analyzed. C.M. Goplen, S.H. Kang and C.A. Jones wrote the article, which all authors critically revised. All authors gave final approval of the article to be published.

Content licence: This is an Open Access article distributed in accordance with the terms of the Creative Commons Attribution (CC BYNCND 4.0) licence, which permits use, distribution and reproduction in any medium, provided that the original publication is properly cited, the use is noncommercial (i.e., research or educational use), and no modifications or adaptations are made. See: https://creativecommons. org/licenses/ by-nc-nd/4.0/.

Funding: This work was supported by Clinical Research Grant RES0039945 from the Department of Surgery, University of Alberta.

\section{References}

1. Busse JW, editor. The 2017 Canadian Guideline for Opioids for Chronic Non-Cancer Pain. Hamilton (ON): National Pain Centre, McMaster University; 2017.

2. Busse JW, Wang L, Kamaleldin M, et al. Opioids for chronic noncancer pain: a systematic review and meta-analysis $7 A M A$ 2018;320: 2448-60.

3. Krebs EE, Gravely A, Nugent S, et al. Effect of opioid vs nonopioid medications on pain-related function in patients with chronic back pain or hip or knee osteoarthritis pain: the SPACE randomized clinical trial. FAMA 2018;319:872-82.

4. Fischer B, Rehm J, Tyndall M. Effective Canadian policy to reduce harms from prescription opioids: learning from past failures. CMAJ 2016;188:1240-4.

5. Dowell D, Haegerich TM, Chou R. CDC Guideline for Prescribing Opioids for Chronic Pain - United States, 2016. 7AMA 2016;315: 1624-45.

6. Ben-Ari A, Chansky H, Rozet I. Preoperative opioid use is associated with early revision after total knee arthroplasty: a study of male patients treated in the Veterans Affairs system. $\mathcal{F}$ Bone Foint Surg Am 2017;99:1-9

7. Bedard NA, Pugely AJ, Westermann RW, et al. Opioid use after total knee arthroplasty: trends and risk factors for prolonged use. $\mathcal{F}$ Artbroplasty 2017;32:2390-4.

8. Kim KY, Anoushiravani AA, Chen KK, et al. Preoperative chronic opioid users in total knee arthroplasty - Which patients persistently abuse opiates following surgery? 7 Arthroplasty 2017; 33: 107-12.

9. Hernandez NM, Parry JA, Taunton MJ. Patients at risk: large opioid prescriptions after total knee arthroplasty. 7 Arthroplasty 2017;32: 2395-8.

10. Scully RE, Schoenfeld AJ, Jiang W, et al. Defining optimal length of opioid pain medication prescription after common surgical procedures. 7AMA Surg 2018;153:37-43.

11. Rozell JC, Courtney PM, Dattilo JR, et al. Preoperative opiate use independently predicts narcotic consumption and complications after total joint arthroplasty. 7 Arthroplasty 2017;32:2658-62.

12. Agrawal Y, Smith RM, Garbuz DS, et al. Opioids in arthroplasty: mind the gap between North America and the rest of the world. $\mathcal{F}$ Bone foint Surg Am 2018;100:2162-71.

13. Nguyen LCL, Sing DC, Bozic KJ. Preoperative reduction of opioid use before total joint arthroplasty. 7 Arthroplasty 2016;31:282-7. 
14. Goesling J, Moser SE, Zaidi B, et al. Trends and predictors of opioid use after total knee and total hip arthroplasty. Pain 2016;157:1259-65.

15. Zywiel MG, Stroh DA, Lee SY, et al. Chronic opioid use prior to total knee arthroplasty. F Bone foint Surg Am 2011;93:1988-93.

16. Sing DC, Barry JJ, Cheah JW, et al. Long-acting opioid use independently predicts perioperative complication in total joint arthroplasty. 7 Arthroplasty 2016;31(9 Suppl):170-4.e1.

17. Franklin PD, Karbassi JA, Li W, et al. Reduction in narcotic use after primary total knee arthroplasty and association with patient pain relief and satisfaction. F Arthroplasty 2010;25(Suppl 6):12-6.

18. Lavernia CJ, Alcerro JC, Contreras JS. Knee arthroplasty: growing trends and future problems. Int 7 Clin Rheumatol 2010;5:565-79.

19. Wylde V, Trela-Larsen L, Whitehouse MR, et al. Preoperative psychosocial risk factors for poor outcomes at 1 and 5 years after total knee replacement. Acta Orthop 2017;88:530-6.

20. Sullivan MD. Depression effects on long-term prescription opioid use, abuse, and addiction. Clin $\mathcal{F}$ Pain 2018;34:878-84.

21. von Elm E, Altman DG, Egger M, et al. The Strengthening the Reporting of Observational Studies in Epidemiology (STROBE) statement: guidelines for reporting observational studies. 7 Clin Epidemiol 2008;61:344-9.

22. Compensation Practice Directive: \#C10-1 - Claims with opioids, sedatives/hypnotics or other prescribed potentially addictive drugs. Vancouver: WorkSafeBC; 2015. Available: https://www.worksafebc. com/en/resources/law-policy/compensation-practice-directives/claims -with-opioids-sedativehypnotics-or-other-prescribed-potentially -addictive-drugs?lang=en \& origin=s\& returnurl=https $\% 3 \mathrm{~A} \% 2 \mathrm{~F} \% 2$ Fwww.worksafebc.com\%2Fen\%2Fsearch\%23q\%3DOpioi (accessed 2019 Nov. 1).

23. Cancer pain relief. Geneva: World Health Organization; 1986.

24. Collins NJ, Roos EM. Patient-reported outcomes for total hip and knee arthroplasty: commonly used instruments and attributes of a "good" measure. Clin Geriatr Med 2012;28:367-94.

25. Chou R, Fanciullo GJ, Fine PG, et al. Clinical guidelines for the use of chronic opioid therapy in chronic noncancer pain. 7 Pain 2009; 10:113-30.e22.

26. Vanderlip ER, Sullivan MD, Edlund MJ, et al. National study of discontinuation of long-term opioid therapy among veterans. Pain 2014; 155:2673-9.

27. Calcaterra SL, Scarbro S, Hull ML, et al. Prediction of future chronic opioid use among hospitalized patients. 7 Gen Intern Med 2018;33:898-905.

28. Hadlandsmyth K, Vander Weg MW, McCoy KD, et al. Risk for prolonged opioid use following total knee arthroplasty in veterans. $\mathcal{F}$ Arthroplasty 2018;33:119-23.

29. Van Wijk BLG, Klungel OH, Heerdink ER, et al. Refill persistence with chronic medication assessed from a pharmacy database was influenced by method of calculation. 7 Clin Epidemiol 2006;59:11-7.

30. Sullivan $M$, Tanzer $M$, Stanish $W$, et al. Psychological determinants of problematic outcomes following total knee arthroplasty. Pain 2009;143:123-9.

31. Harmelink KEM, Zeegers AVCM, Hullegie W, et al. Are there prognostic factors for one-year outcome after total knee arthroplasty? A systematic review. F Artbroplasty 2017;32:3840-53.
32. Podmore B, Hutchings A, van der Meulen J, et al. Impact of comorbid conditions on outcomes of hip and knee replacement surgery: a systematic review and meta-analysis. BMF Open 2018; 8:e021784.

33. Amusat N, Beaupre L, Jhangri GS, et al. Diabetes that impacts on routine activities predicts slower recovery after total knee arthroplasty: an observational study. F Physiother 2014;60:217-23.

34. Gu A, Wei C, Maybee CM, et al. The impact of chronic obstructive pulmonary disease on postoperative outcomes in patients undergoing revision total knee arthroplasty. F Artbroplasty 2018;33:2956-60.

35. Seol YJ, Yoon TR, Lee DH, et al. Outcome analysis of hip or knee arthroplasty in patients with cirrhotic liver disease. 7 Orthop 2017;14: 171-5.

36. Lizaur-Utrilla A, Martinez-Mendez D, Collados-Maestre I, et al. Elective total knee arthroplasty in patients with end-stage renal disease: Is it a safe procedure? 7 Artbroplasty 2016;31:2152-5.

37. Politzer CS, Kildow BJ, Goltz DE, et al. Trends in opioid utilization before and after total knee arthroplasty. 7 Arthroplasty 2018;33:S14753.e1.

38. Pivec R, Issa K, Naziri Q, et al. Opioid use prior to total hip arthroplasty leads to worse clinical outcomes. Int Orthop 2014;38:1159-65.

39. Smith SR, Collins JE, Yang H, et al. Impact of preoperative opioid use on total knee arthroplasty outcomes. 7 Bone foint Surg Am 2017; 99:803-8.

40. Clement ND, Bardgett $M$, Weir D, et al. What is the minimum clinically important difference for the WOMAC Index after TKA? Clin Orthop Relat Res 2018;476:2005-14.

41. Carullo V, Fitz-James I, Delphin E. Opioid-induced hyperalgesia: a diagnostic dilemma. 7 Pain Palliat Care Pharmacother 2015; 29:378-84.

42. Chu LF, Clark DJ, Angst MS. Opioid tolerance and hyperalgesia in chronic pain patients after one month of oral morphine therapy: a preliminary prospective study. 7 Pain 2006;7:43-8.

43. Cohen SP, Christo PJ, Wang S, et al. The effect of opioid dose and treatment duration on the perception of a painful standardized clinical stimulus. Reg Anesth Pain Med 2008;33:199-206.

44. Kim SC, Choudhry N, Franklin JM, et al. Patterns and predictors of persistent opioid use following hip or knee arthroplasty. Osteoarthritis Cartilage 2017;25:1399-406.

45. Hansen CA, Inacio MCS, Pratt NL, et al. Chronic use of opioids before and after total knee arthroplasty: a retrospective cohort study. 7 Arthroplasty 2017;32:811-817.e1.

46. Shah A, Hayes CJ, Martin BC. Characteristics of initial prescription episodes and likelihood of long-term opioid use - United States, 2006-2015. MMWR Morb Mortal Wkly Rep 2017;66:265-9.

47. Stirratt MJ, Dunbar-Jacob J, Crane HM, et al. Self-report measures of medication adherence behavior: recommendations on optimal use. Transl Behav Med 2015;5:470-82.

48. Hereford TE, Cryar KA, Edwards PK, et al. Patients with hip or knee arthritis underreport narcotic usage. 7 Arthroplasty 2018;33: 3113-7.

49. Choi JK, Geller JA, Patrick DA Jr, et al. How are those "lost to follow-up" patients really doing? A compliance comparison in arthroplasty patients. World f Orthop 2015;6:150-5. 